\title{
Self-assembled molecular squares as supramolecular tectons
}

Shobhana Krishnaswamy $^{1}$, Soumyakanta Prusty ${ }^{1}$, Daniel Chartrand ${ }^{2}$, Garry Hanan ${ }^{2}$, Dillip Kumar Chand ${ }^{1}$ ${ }^{1}$ Dept. Of Chemistry, Indian Institute Of Technology Madras, Chennai, India, ${ }^{2}$ Dept. of Chemistry, University of Montreal, Montreal, Canada

E-mail: cy14ipf04@smail.iitm.ac.in

A concentration dependent equilibrating mixture of molecular squares $\left[\mathrm{Pd} 4\left(\mathrm{~L}^{\prime}\right) 4(\mathrm{~L}) 4\right](\mathrm{NO} 3) 8$ and triangles $\left[\mathrm{Pd} 3\left(\mathrm{~L}^{\prime}\right) 3(\mathrm{~L}) 3\right]$ (NO3)6 was obtained when cis-protected $\mathrm{Pd}(\mathrm{II})$ units $\left[\mathrm{Pd}\left(\mathrm{L}^{\prime}\right)(\mathrm{NO} 3) 2\right]\left(\mathrm{L}^{\prime}=\right.$ tmeda, $[1] 2,2^{\prime}$-bpy, [2] phen) were combined in turn with $4,4^{\prime}$-bipyridine $(L)$ in water. The addition of AgOTs to the mixture led to a shift in the equilibrium, resulting in the disappearance of the triangles and exclusive formation of the squares in case of all the complexes. The crystal structures of the molecular squares $\left[\mathrm{Pd} 4\left(\mathrm{~L}^{\prime}\right) 4(\mathrm{~L}) 4\right](\mathrm{OTs}) 8$ revealed a pair of tosylate anions encapsulated in the hydrophobic cavity of the square and the presence of several water molecules outside the cavity. The complexes [Pd4(bpy)4(L)4](OTs)8 and [Pd4(phen)4(L)4] (OTs)8 exhibited solvatomorphism and yielded two crystalline forms each, respectively. The cationic units in these crystals associate through п...п stacking interactions between the aromatic rings of the four bpy/phen units and form either one-dimensional arrays or two-dimensional layers. The formation of a one-dimensional array occurs when one pair of bpy/phen units of the square engage in п...п stacking interactions with the tosylate anions instead of other adjacent bpy/phen units. Therefore, the cations in the bpy and phen squares may be considered as 'tectons' which contain four supramolecular 'synthons' apiece, i.e. the cis-protecting units bpy/phen. The knowledge of common patterns of molecular association and identification of supramolecular synthons in these structures can help in the crystal engineering of coordination compounds with desired solid-state properties/functions.

[1] Uehara, K. et al. (2007). Inorg. Chem., 46, 2563-2570.

[2] Fujita, M. et al. (1996). Chem. Commun., 1535-1536.
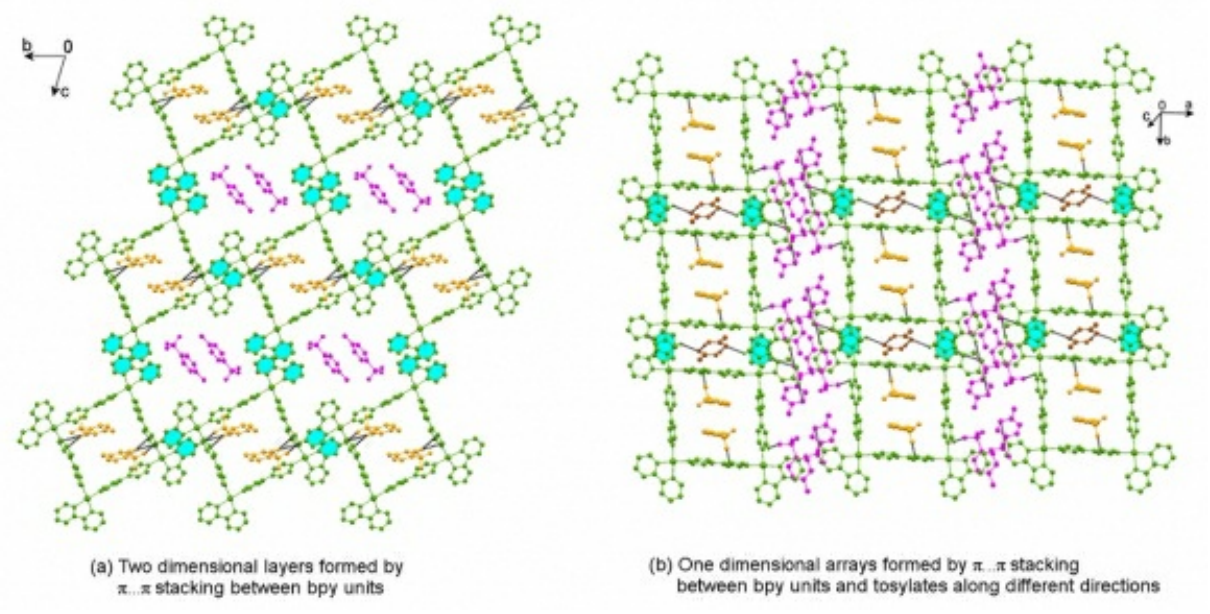

Keywords: crystal engineering, Pd(II) molecular square, solvatomorphism 